\title{
EVIDENCIA DE SEGURIDAD EN EL USO DE IVERMECTINA EN GESTANTES: A PROPÓSITO DEL EMPLEO DE IVERMECTINA EN COUID-19
}

\author{
SAFETY EVIDENCE IN THE USE OF IVERMECTIN IN PREGNANTS: \\ A PURPOSE OF THE USE OF IVERMECTIN IN COVID-19
}

Daisy Flores-Cortez (iD) 1,a

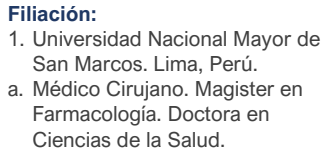

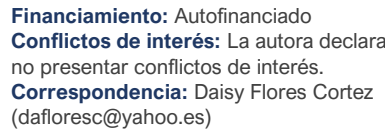

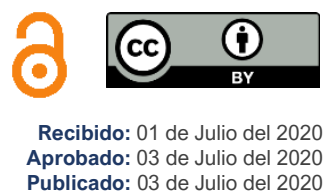

\author{
Citar como: Flores-Cortez D. Evidencia \\ gestantes: A propósito del empleo de \\ ivermectina en COVID-19. Revista Internaciona \\ de Salud Materno Fetal. 2020; 5 (2): 1-3.
}

La Ivermectina, medicamento derivado macrocíclico formado por una mezcla 80:20 de avermectina B1a y B1b, se ha utilizado por más de 30 años para tratar diversas enfermedades parasitarias en mamíferos, fue aprobada por la Food and Drug Administration (FDA) para el tratamiento de la oncocercosis y la estrongiloidiasis, y en otros países se incluyó su empleo en escabiosis y pediculosis; sin embargo, su espectro de acción incluye a múltiples endo y ectoparásitos (1); así como su eficacia comprobada para la prevención y control de la malaria (2). En un reciente estudio in vitro en células Vero/hSLAM infectadas con el virus SARS-CoV-2 (COVID-19) expuestas a Ivermectina $5 \mu \mathrm{M}$; después de 48 horas, se encontró una reducción del ARN viral en 5000 veces comparado con el grupo control (3). Desde entonces, más de 30 ensayos clínicos se encuentran en fase de reclutamiento para evaluar la eficacia de Ivermectina en el tratamiento o profilaxis de SARS-CoV-2; por lo que se estima que en los próximos meses se tengan resultados publicados al respecto $(4,5)$.

En nuestro país, directivas del Ministerio de Salud (MINSA), han incluido la Ivermectina en el documento técnico para el tratamiento de los casos confirmados de COVID-19, indicando su uso previo consentimiento informado, y sobre la base de una evaluación individual del paciente, bajo supervisión y monitoreo estricto del profesional médico tratante, tanto del cuadro clínico como de las reacciones adversas asociadas al fármaco prescrito (6). Sin embargo, no menciona su empleo en gestantes o mujeres en periodo de lactancia.

El uso masivo y la automedicación con Ivermectina para el tratamiento de coronavirus, viene ocurriendo en diversas regiones de nuestro país, lo que conlleva un riesgo latente de uso en la gestante infectada; por lo que es recomendable hacer una revisión de las evidencias actuales del efecto adverso materno fetal de este fármaco.

Aunque sólo hay un ensayo clínico realizado con Ivermectina en gestantes; la mayoría de las evidencias recopiladas a lo largo de más de 30 años surgen del uso accidental o inadvertido en gestantes con diversas condiciones infecciosas. Se estima que en las áreas endémicas de oncocercosis, hasta el 50\% de gestantes en el primer trimestre fueron tratadas inadvertidamente con Ivermectina durante campañas comunitarias a gran escala en zonas de alto riesgo (7).

Recientemente, una revisión sistemática y metaanálisis realizada por Nicolas et al (8) incluyó 1 ensayo clínico controlado aleatorio (ECA) y 5 estudios observacionales caso control, publicados entre 1990 y 2008. En los estudios observacionales se usó Ivermectina inadvertidamente en 496 mujeres embarazadas a una dosis de $150 \mu \mathrm{g} / \mathrm{kg}$ o más en cualquier momento del embarazo. En el ensayo clínico, 397 mujeres embarazadas recibieron Ivermectina intencionalmente, asociado o no a Albendazol, para el tratamiento de helmintiasis. Los estudios observacionales informaron 31 abortos espontáneos y muertes fetales de 446 resultados de 
gestaciones expuestas a Ivermectina, en comparación con 135 casos de 2603 gestantes control (OR:1.15; IC-95\%:0.75-1.78); aunque se observa un 15\% de riesgo de aborto y muerte fetal en el grupo Ivermectina, este incremento no fue estadísticamente significativo. En los resultados del ECA no se observaron diferencias entre abortos espontáneos y muertes fetales ante la exposición a Ivermectina respecto a la exposición de Ivermectina en combinación con Albendazol durante el segundo y tercer trimestre (OR:0.62; IC95\%:0.18-2.14). Respecto a las anomalías congénitas, en los estudios observacionales se evidenciaron $12 / 500$ en mujeres tratadas con Ivermectina, en comparación con 33/2666 en el grupo control (OR:1.69; IC95\%:0.833.41). En el ECA tampoco se presentó una diferencia significativa de anomalías congénitas entre los grupos evaluados (OR:1.10; IC95\%:0.07-17.65). Además, ningún estudio informó muertes neonatales, morbilidad materna, nacimientos prematuros o bajo peso al nacer. Pese a los resultados encontrados, no se puede considerar que éstos tengan un alto nivel de evidencia debido a que todos los estudios presentaron sesgos en la selección, comparabilidad entre los grupos y en la exposición a la Ivermectina; por tanto, la certeza de la evidencia de los estudios se evaluó como muy baja utilizando el enfoque GRADE.

Adicionalmente, un ensayo clínico publicado por Burnham (9) acerca de las reacciones adversas a la Ivermectina administrada anualmente para tratamiento de oncocercosis; reportó que tres mujeres embarazadas fueron tratadas inadvertidamente con Ivermectina durante el ensayo, siendo el curso del embarazo y parto normal y no se observó anormalidad en los recién nacidos.

En las mujeres que amamantan, se ha demostrado que los niveles de Ivermectina se encuentran bajos en la leche materna humana después de una dosis oral única de 150-250 mcg/kg en mujeres sanas con un pico a 1 hora después de la ingestión de $18,5 \mathrm{ng} / \mathrm{ml}$ y sigue siendo detectable en la leche humana a muy bajos niveles ( $<1 \mathrm{ng} / \mathrm{ml}$ ) hasta 14 días después de una dosis única; por tanto no se sugeriría la exclusión de su uso en madres lactantes (10). En otro reporte se señala que los niveles de Ivermectina en la leche materna oscilaron entre 1,4 y $20,8 \mathrm{ng} / \mathrm{ml}$, con una media de $9,26 \mathrm{ng} / \mathrm{ml}$ después de una dosis única de $200 \mu \mathrm{g} / \mathrm{kg}$. Se estimó que la posible exposición a Ivermectina en el lactante es de $1.1 \mu \mathrm{g} / \mathrm{kg}, 0.55 \%$ del porcentaje de la dosis materna ajustada por peso. Este valor está en gran medida por debajo del umbral establecido por la Organización Mundial de la Salud para la lactancia materna segura (11).

En conclusión, no hay evidencia suficiente para concluir de manera fehaciente sobre el perfil de seguridad de la Ivermectina durante el embarazo y la lactancia; sin embargo, el médico debe valorar la relación riesgo-beneficio de su empleo en el tratamiento de COVID-19; así mismo se debe asegurar que su uso corresponda a las concentraciones y formas farmacéuticas aprobadas para uso en humanos. 


\section{REFERENCIAS}

1. Victoria J. Ivermectina: Sus Múltiples Usos, Seguridad y Toxicidad. Rev Chil Dermatol. 2010;26(4):358-68. [Link]

2. Chaccour C, Hammann F, Rabinovich NR. Ivermectin to reduce malaria transmission I. Pharmacokinetic and pharmacodynamic considerations regarding efficacy and safety. Malar $\mathrm{J}$. 2017;16(1):1-16. [Link]

3. Caly L, Druce JD, Catton MG, Jans DA, Wagstaff KM. The FDA-approved drug ivermectin inhibits the replication of SARS-CoV-2 in vitro. Antiviral Res. 2020 Jun 1;178:104787. [Link]

4. US National Library Medicine. Clinical Trials on Ivermectin in SARS-COV2. ClinicalTrials.gov. 2020 [cited 2020 Jun 29].7. [Link]

5. Chaccour C, Ruiz-Castillo Richardson M-A, Moncunill

\section{$P$,} $\mathrm{G}$,
Casellas A, Carmona-Torre $\mathrm{F}$, et al. The SARS-CoV-2 Ivermectin NavarraISGlobal Trial (SAINT) to Evaluate the Potential of Ivermectin to Reduce COVID-19 Transmission in low risk, non-severe COVID-19 patients in the first 48 hours after symptoms onset: A structured summary of a study protocol. Trials. 2020 Jun 8 [cited 2020 Jun 20];21(1):498. [Link]

6. Ministerio de Salud (Perú). RM2702020: Documento técnico: Prevención, diagnóstico y tratamiento de personas afectadas por COVID-19 en el Perú. Lima - Perú: MINSA; 2020. [Link]

7. Pacqué $M$, Muñoz B, Poetscke $G$, Foose J, Taylor HR, Greene BM. Pregnancy outcome after inadvertent ivermectin treatment during community-based distribution. Lancet. 1990 Dec 15;336(8729):1486-9. [Link]

Nicolas P, Maia MF, Bassat $Q$, Kobylinski KC, Monteiro W,
Rabinovich NR, et al. Safety of oral ivermectin during pregnancy: a systematic review and meta-analysis. Lancet Glob Heal. 2020 Jan 1;8(1):e92-100. [Link]

9. Burham GM. Adverse reactions to ivermectin treatment for onchocerciasis. Results of a placebocontrolled, double-bling trial in Malawi. Trans R Soc Trop Med Hyg. 1993; 87(3): 313-7. [Link]

10. Ogbuokiri JE, Ozumba BC, Okonkwo PO. Ivermectin levels in human breastmilk. Eur J Clin Pharmacol. 1993 Nov; 45(4):389-90. [Link]

11. Rodari P, Buonfrate D, Pomari E, Lunardi G, Bon I, Bisoffi Z, et al. Ivermectin concentration in breastmilk of a woman with Strongyloides stercoralis and human T-lymphotropic virus-I co-infection. Acta Trop. 2020;202:105249. [Link] 